\title{
« Un nouveau bas-relief d'Élymaïde à 'Shirinow' sur un passage de la migration des Baxtyaris ». IA, 35, (2000), pp. 57-68.
}

\section{Rémy Boucharlat}

\section{(2) OpenEdition}

1 Journals

Édition électronique

URL : http://journals.openedition.org/abstractairanica/35313

DOI : 10.4000/abstractairanica.35313

ISSN : 1961-960X

Éditeur :

CNRS (UMR 7528 Mondes iraniens et indiens), Éditions de l'IFRI

\section{Édition imprimée}

Date de publication : 15 mai 2002

ISSN : 0240-8910

Référence électronique

Rémy Boucharlat, « « Un nouveau bas-relief d'Élymaïde à 'Shirinow' sur un passage de la migration des Baxtyaris ». IA, 35, (2000), pp. 57-68. », Abstracta Iranica [En ligne], Volume 23 | 2002, document 99, mis en ligne le 08 février 2010, consulté le 25 septembre 2020. URL : http://journals.openedition.org/ abstractairanica/35313 ; DOI : https://doi.org/10.4000/abstractairanica.35313

Ce document a été généré automatiquement le 25 septembre 2020.

Tous droits réservés 


\title{
« Un nouveau bas-relief d'Élymaïde à 'Shirinow' sur un passage de la migration des Baxtyaris ». IA, 35, (2000), pp. 57-68.
}

\author{
Rémy Boucharlat
}

1 Les principaux bas-reliefs d'époque parthe de cette région du Zagros ont été découverts entre 1841 et 1974 (voir Vanden Berghe et Schippmann, Les reliefs rupestres d'Élymaïde, Iran, 1985). Depuis, ce sont surtout les explorations de l'A. qui ont apporté de nouveaux témoins, en général plus modestes, de cet art élyméen, à dater des $1^{\mathrm{er}}$ et $2^{\mathrm{e}} \mathrm{s}$. d.n.è. pour la plupart d'entre eux (tableau des découvertes p. 67). Le thème principal reste celui de l'hommage à un prince ou un dignitaire. De ces personnages et de la population de la région, nous ne savons presque rien.

INDEX

Thèmes : 3.2.3. Séleucides, Parthes et Sassanides

\section{AUTEURS}

RÉMY BOUCHARLAT

CNRS - Lyon 